Tropical Journal of Pharmaceutical Research October 2013; 12 (5): 791-798

ISSN: $1596-5996$ (print); 1596-9827 (electronic) (C) Pharmacotherapy Group, Faculty of Pharmacy, University of Benin, Benin City, 300001 Nigeria.

All rights reserved.

Available online at http://www.tjpr.org

Original Research Article

http://dx.doi.org/10.4314/tjpr.v12i5.20

\title{
An Efficient, Green Chemical Synthesis of the Malaria Drug, Piperaquine
}

\section{Joseph MD Fortunak ${ }^{1^{*}}$, Stephen R Byrn ${ }^{2}$, Brandon Dyson ${ }^{1}$, Zita Ekeocha ${ }^{3}$, Tiffany Ellison ${ }^{1}$, Christopher L King ${ }^{1}$, Amol A Kulkarni ${ }^{4}$, Mindy Lee ${ }^{1}$, Chelsea Conrad $^{1}$ and Keeshaloy Thompson ${ }^{1}$}

${ }^{1}$ Department of Chemistry, Howard University, Washington, DC, 20059, ${ }^{2}$ Department of Industrial and Physical Pharmacy, Purdue University, West Lafayette, IN 47907 USA, ${ }^{3}$ St Luke Foundation - Kilimanjaro School of Pharmacy, Industrial Pharmacy Training Unit, PO Box 481, Moshi, Tanzania, ${ }^{4}$ Department of Pharmaceutical Sciences, Howard University, Washington, DC, USA 20059, ${ }^{5}$ National Institute for Pharmaceutical Research \& Development, Federal Ministry of Health, P.M.B. 21, Industrial Layout, Abuja, Nigeria

*For correspondence: Email: jfortunak@comcast.net

\begin{abstract}
Purpose: To provide a robust, efficient synthesis of the malaria drug piperaquine for potential use in resource-poor settings.

Methods: We used in-process analytical technologies (IPAT; HPLC) and a program of experiments to develop a synthesis of piperaquine that avoids the presence of a toxic impurity in the API and is optimized for overall yield and operational simplicity.

Results : A green-chemical synthesis of piperaquine is described that proceeds in $92-93 \%$ overall yield. The chemistry is robust and provides very pure piperaquine tetraphosphate salt (>99.5\%). The overall process utilizes modest amounts (about $8 \mathrm{~kg} / \mathrm{kg}$ ) of 2-propanol and ethyl acetate as the only organic materials not incorporated into the API; roughly $60 \%$ of this waste can be recycled into the production process. This process also completely avoids the formation of a toxic impurity commonly seen in piperaquine that is otherwise difficult to remove.

Conclusion: An efficient synthesis of piperaquine is described that may be useful for application in resource-poor settings as a means of expanding access to and reducing the cost of ACTs.
\end{abstract}

Keywords: ACTs, Dihydroartemisinin Piperaquine, Dihydroartemisinin, Green Chemistry, Malaria, Piperaquine.

Tropical Journal of Pharmaceutical Research is indexed by Science Citation Index (SciSearch), Scopus, International Pharmaceutical Abstract, Chemical Abstracts, Embase, Index Copernicus, EBSCO, African Index Medicus, JournalSeek, Journal Citation Reports/Science Edition, Directory of Open Access Journals (DOAJ), African Journal Online, Bioline International, Open-J-Gate and Pharmacy Abstracts

\section{INTRODUCTION}

A high level of global awareness has been generated of the mortality, morbidity and economic burden resulting from lack of essential medicines in resource-poor settings [1]. Several International Donor Agencies target increased access to essential medicines. Artemisinin Combination Therapies (ACTs) are recommended by the World Health Organization for the treatment of uncomplicated malaria. The combination of dihydroartemisinin + piperaquine (DHAP) has demonstrated superior efficacy and post-treatment prophylaxis against Plasmodial forms of malaria (Figure 1) [2]. Two major donor agencies, GFATM (the Global Fund for AIDS, Tuberculosis and Malaria) and PEPFAR (US President's Emergency Plan for AIDS Relief), provide several billion USD each year for the management of HIVIAIDS, malaria, and other 


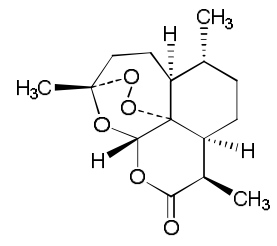

Artemisinin

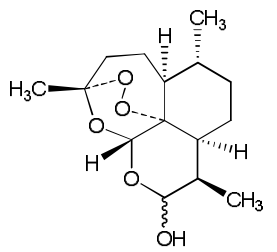

Dihydroartemisinin

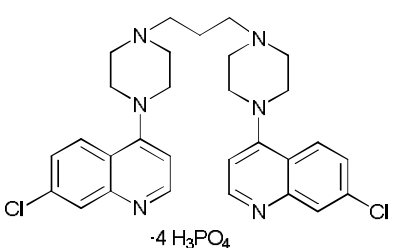

Piperaquine

Figure 1. Artemisinin, piperaquine, dihydroartemisinin.

neglected diseases [3]. The Affordable Medicines Facility for Malaria (AMFm) is an innovative financing mechanism intended to expand access to malaria medicines through public, private, and non-Governmental (NGO) mechanisms [4]. AMFm strategies include subsidies to assure the cost-competitiveness of ACTs in the marketplace, and the utilization of ACTs in preference to less effective treatments [5]. A primary reason for the use of ACTs is the emergence of plasmodial strains that are resistant to older drugs such as chloroquine [6]. Half of the world's population is at risk for malaria; 243 million new infections were estimated to have occurred in 2006 [7]. Malaria caused approximately 863000 deaths in 2008 [8]. About $91 \%$ of malaria deaths in 2006 occurred in Africa; $85 \%$ of these were children under the age of five [9]. The most deadly infectious strain, Plasmodium falciparum ( $P$. falciparum) is among the leading causes of death worldwide from a single infectious agent. Four major tactics utilized for malaria control are (1) the eradication of mosquito breeding grounds; (2) internal residual spraying; (3) the use of chemically-treated bed nets to prevent transmission; and (4) effective chemotherapy for infected individuals [10]. Effective chemotherapy for uncomplicated malaria is predominately based on the use of a semisynthetic derivative of artemisinin in combination with a synthetic malaria drug to reliably provide high rates of remission. The artemisinin-derived component of an ACT rapidly clears parasites from circulating blood plasma, but has a relatively short half-life (a few hours). The synthetic component of an ACT has a long residence time in tissues (days, or even weeks), to prevent the re-emergence of symptomatic infection. The WHO Essential Medicines List (EML) includes ACT combination therapies. Drug purchases by the AMFm and other NGOs are limited to suppliers who assure the quality of their products according to Strict Regulatory Authority (SRA) guidelines. Good Manufacturing Practice (GMP) is required of all drug manufacturers. Each product for every manufacturer is approved based upon the combination of a review of an appropriate regulatory dossier and an on-site inspection to assure the validated quality and consistency of production. SRAs include the World Health Organization's Prequalification Program for medicines (WHO PQP) [11] and the US FDA [12]; both of these organizations draw very heavily from the concepts and documentation of the International Conference on Harmonization of Technical Requirements for the Registration of Pharmaceuticals for Human Use (ICH) [13]. The QAMSA (Quality of Anti-malarials in SubSaharan Africa) study found huge differences in the failure rates of malaria medicines which had been pre-qualified by the WHO PQP (4 \%) versus those which were not SRA-approved (40 \%) [14].

Regional (private sector) pharmaceutical companies exist in most African countries. Tanzania and Kenya are two East African countries with individual populations of $35-45$ million people. Recent data indicates that twenty pharmaceutical manufacturing companies are operating in Kenya and another nine in Tanzania $[15,16]$. Only two African companies are known to be involved in the commercial cultivation, isolation and purification of artemisinin for ACTs production [17]. Most African pharmaceutical companies purchase Active Pharmaceutical Ingredients from India or China and prepare finished dosage forms for sale. No African companies currently manufacture their own APIs for ACTs on commercial scale. The Republic of South Africa is the only National Drug Regulatory Agency in Sub-Saharan Africa currently approved as an SRA. The inspection and approval of companies in Sub-Saharan Africa to verify GMP status and Quality-Assurance, therefore, is carried out by SRAs external to the country of origin - largely the WHO PQP, PIC/S, and the US FDA.

Our work in Africa is intended to (1) enable regional pharmaceutical companies to achieve SRA approval for medicines production; (2) to enable National Drug Regulatory Agencies to achieve SRA status; and (3) to eliminate counterfeit and substandard medicines. We teach the principles of drug development, GMP 
and quality-assurance for drug production and the preparation of Regulatory dossiers to pharmaceutical professionals and National Drug Regulators as a means of achieving these ends. Training takes place at the Saint Luke Foundation / Kilimanjaro School of Pharmacy (SLF/KSP) in Moshi, Tanzania. Funding for this program has been partially subsidized to date (2012) by the United Nations Industrial Development Organization (UNIDO). We have concluded that a priority means of expanding access to quality-assured medicines should be by raising the quality of local production and drug regulation in Africa to meet international standards, and to enable local producers to sell their products to GFATM and PEPFAR through their country Ministry of Health. The WHOrecommends the use of ACTs for all patients who can tolerate them [18]. ACTs currently recommended for use in the treatment of uncomplicated malaria are artemetherlumefantrine (ALU), artesunate-amodiaquine (ASAQ), artesunate-mefloquine (ASM), artesunate-sulfadoxine-pyrimethamine (ASSP) and dihydroartemisinin-piperaquine (DHAP). The combination of dihydroartemisinin + piperaquine in fixed-dose combination tablets containing $50 / 135 \mathrm{mg}$ or $100 / 270 \mathrm{mg}$ of aretmisinin and PQ is a safe, well-tolerated, and highly effective treatment for $P$. falciparum malaria in Asia and Africa [19]. DHAP is a relatively recent ACT that is recommended for first-line treatment in Vietnam (2007) and is rapidly gaining in popularity in Africa because of its reliability, cost, and rapid onset of action. DHAP manufactured by Sigma Tau was recently (2011) added to the WHO Model List of Essential Medicines [20].

The purpose of this work was to provide a robust, efficient synthesis of the malaria drug piperaquine for potential use in resource-poor settings.

\section{EXPERIMENTAL}

${ }^{1} \mathrm{H}$ and ${ }^{13} \mathrm{C}$ NMR spectra were recorded using Bruker spectrometer (400 MHz and $101 \mathrm{MHz}$ ). ${ }^{1} \mathrm{H}$ NMR chemical shifts are reported in ppm using the deuterated solvent chloroform $\left(\mathrm{CDCl}_{3}\right)$ or dimethylsulfoxide (DMSO, $\mathrm{D}_{6}$ ) as calibration standards $\left(\mathrm{CDCl}_{3}\right.$ : 7.27 ppm, DMSO: 2.49 ppm). The data are reported as follows: chemical shift, multiplicity $(\mathrm{s}=$ singlet; $\mathrm{d}=$ doublet; $\mathrm{t}=$ triplet; $\mathrm{q}=$

quartet; mult = multiplet), coupling constants $(\mathrm{Hz})$, integration. ${ }^{13} \mathrm{C}$ NMR chemical shifts are reported in ppm using the deuterated solvent $\mathrm{CDCl}_{3}$ (77.0 ppm) or DMSO, $\mathrm{D}_{6}(39.5 \mathrm{ppm})$ as calibration standard. ${ }^{13} \mathrm{C}$ NMR was obtained with complete proton decoupling. DEPT-135, COSY, HETCOR recorded using Bruker spectrometer (400 MHz).

Mass spectra (exact mass) recorded using LS/MS 1260 Series Infinity Agilent Technologies Analytical Instrument equipped with 6224 Time of Flight (TOF) LS/MS Spectrometer. HPLC was performed using 1200 Series Agilent Technologies Analytical Instrument equipped with a diode array UV detector. Melting points were obtained on an Electrothermal Mel-Temp apparatus and are uncorrected.

Piperaquine phosphate (tetraphosphate salt) from Mangalam Chemical (India) was used as a reference standard. 4,7-Dichloroquinoline (DCQ; $97 \%$ ), piperazine (97\%), 1,3-dibromopropane (99\%), ethyl acetate and 2-propanol (reagent grade) were purchased from Sigma-Aldrich Corporation and used as received. Potassium carbonate and phosphoric acid (85\% aqueous $\mathrm{H}_{3} \mathrm{PO}_{4}$ ) were purchased from Mallinckrodt and used as received. Water met the local requirements for potable water.

Reverse-phase high-pressure liquid chromatography (HPLC) was carried out with 1200 Series Agilent Technologies analytical instrument equipped with a diode array UV detector. HPLC was initially used to monitor reactions, analyze isolated products, and define the optimal range of processing conditions. Correlation between HPLC and thin-layer chromatography (TLC) demonstrated that TLC is adequate to monitor reactions in progress.

The HPLC mobile phase (isocratic) used was 80:20 acetonitrile:10 mM aqueous phosphate buffer adjusted to $\mathrm{pH} 6.9$ with triethylamine. A Zorbax Extend C18 column, $15 \mathrm{~cm} \times 0.46 \mathrm{~cm}$ ID was used at a flow rate of $1 \mathrm{~mL} / \mathrm{min}$, with UVdetection at a wavelength of $263 \mathrm{nM}$. Injection volume for samples was 1 microliter. This HPLC method was used to monitor both stages of the synthesis; this method is also suitable for determining the absolute purity of piperaquine by w/w analysis

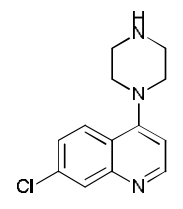

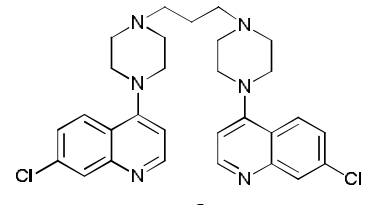

2

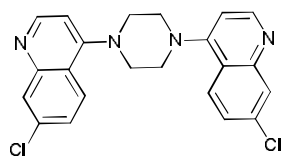

3

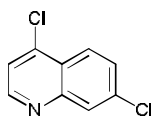

4 


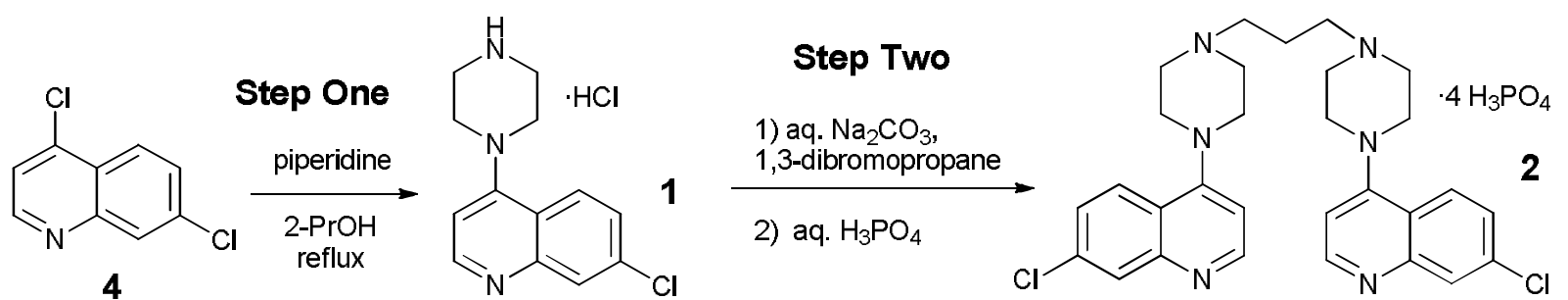

Figure 2: Route of synthesis for piperaquine phosphate<smiles>Clc1ccc2c(Cl)ccnc2c1</smiles><smiles>Clc1ccc2c(N3CCNCC3)ccnc2c1</smiles>

5, FAST

Figure 3: Generation of toxic impurity (3)

Table 1: HPLC retention times and structures of compounds

\begin{tabular}{ll}
\hline Compound & $\begin{array}{l}\text { Retention } \\
\text { time (min) }\end{array}$ \\
\hline 4,7-Dichloro-quinoline (DCQ), 4 & 2.41 \\
Step 1 Product, 1 & 2.55 \\
Piperaquine, 2 (free base) & 4.12 \\
Dimeric impurity, 3 & 7.46 \\
\hline
\end{tabular}

Piperaquine is a well-known, commercial drug, spectra for its identification have been published [21]. Mass Spectra(exact mass) recorded using LS/MS 1260 Series Infinity Agilent Technologies facility while ${ }^{13} \mathrm{C}$ and ${ }^{1} \mathrm{H}$ NMR spectra were recorded using Bruker spectrometer $(400 \mathrm{MHz}$ and $100 \mathrm{MHz}$ ) to confirm the identity of the compounds.

Piperaquine is a member of the 4-aminoquinoline class of antimalarial compounds. Although piperaquine is the sole example of a bis-(4aminoquinoline) drug that is widely approved for the treatment of malaria, quite a number of bisquinolines with powerful activity against malarial parasites are known[22]. Piperaquine and its anti-malarial activity were first disclosed by the pharmaceutical company Rhone-Poulenc in the 1960s[23]. The synthesis is straightforward. Substitution of 4-haloquinolines by amine nucleophiles (Figure 2; Step One, using 4,7dichloroquinoline, 4) is well known; similar chemistry is used to prepare chloroquine, amodiaquine, and structurally-similar malaria drugs[24].
The preparation of 1 from 4,7-dichloroquinoline (DCQ) requires the nucleophilic substitution of a piperazine nitrogen for chloride on the quinoline ring. This reaction is known to have a competing side reaction (Figure 3 ). The step one product is more nucleophilic than piperazine itself, giving rise to a rapid, unwanted side reaction with $\mathrm{DCQ}$ that forms substantial amounts of the toxic, bisquinoline impurity 3.

Previous publications have described the preparation of $1[21,23,25,26]$. Piperazine (a minimum of $3 \mathrm{~mol}$ eq) and DCQ are reacted in 2propanol (7-10 volumes $\mathrm{w} / \mathrm{v})$ at reflux, using potassium carbonate as a base to neutralize the stoichiometric amount of hydrochloric acid that is generated during the displacement reaction. An excess of piperazine is used to minimize the formation of the toxic impurity 3 , although some of this impurity (typically $2-5$ ) is most often observed. Purifying 1 to remove impurity 3 is extremely inefficient. Impurity $\mathbf{3}$ is generally removed by extraction into dichloromethane while the desired product is dissolved in aqueous acid. For step two, previous procedures describe the reaction of 1 with 1-bromo-3-chloropropane or 1,3-dibromopropane in N,N-dimethylformamide (DMF) or another polar, aprotic solvent using potassium carbonate as base. Water has also previously been used as a solvent in step two. In a final operation, the free base of piperaquine is converted into the desired traphosphate salt by the slow addition of phosphoric acid to a suspension of the free base in water. 


\section{Step One}

\section{7-Chloro-4-(1-piperazinyl)-quinoline (1)}

Approximately $250 \mathrm{~mL}$ of 2-propanol was introduced into a round-bottom flask equipped with a stirring apparatus, heating mantle and reflux condenser. 4,7-Dichloroquinoline (100.0 g, $0.50 \mathrm{~mol}$ ) is added via a powder funnel with stirring. The $D C Q$ is observed to readily dissolve in the 2-propanol. Piperazine (130.5 g, $1.51 \mathrm{~mol}$, $3.0 \mathrm{~mol}$ eq) is added as a solid through the powder funnel. The stirred suspension is then heated to reflux, resulting in a golden-yellow solution. The reaction is monitored by TLC for completion (approximately $5.5 \mathrm{~h}$; $80: 20: 4 \mathrm{CHCl}_{3}$ : $\mathrm{MeOH}: \mathrm{AcOH}$, silica gel followed by lodine visualization). When the reaction was vcomplete, the source of heat was removed and stirring continued for approximately $30 \mathrm{~min}$. During this time a white precipitate (mixture of 1 and unreacted piperazine) was observed to form. Ethyl acetate $(700 \mathrm{~mL} ; 7$ volumes $\mathrm{w} / \mathrm{v})$ was added to the stirred suspension over about 5 minutes. Stirring was continued for an additional $2 \mathrm{~h}$ to maximize the precipitation of unreacted piperazine from solution. The suspension was filtered, the filter cake washed with approximately $50 \mathrm{~mL}$ of ethyl acetate, and the combined ethyl acetate layers were washed with $2 \times 350 \mathrm{~mL}$ of water. These extractions removed remaining piperazine from the ethyl acetate layer and 2propanol. The ethyl acetate layer was then concentrated by distillation under reduced pressure to approximately $40 \%$ of its original volume and filtered to isolate Compound 1 as a white solid. The crude Compound 1 was carried on to step two as a wet cake. After drying to a constant weight, approximately $119 \mathrm{~g}$ of 1 was obtained (96\% yield corrected for the purity of $\mathrm{DCQ}$ and 1). DCQ can be purchased with a purity of about $96.5-98.0 \%$ and the 4,5dichloroquinoline isomer is the major impurity present $(1.0-2.5 \%)$. Compound 1 is typically isolated in a purity of $>99.0 \%$ with small amounts of unreacted DCQ (NMT $0.20 \%$ ) and the 5-chloro isomer of 1 (NMT $0.20 \%$ ) present as indicated by HPLC analysis [21]. A white solid, mp: $112-114{ }^{\circ} \mathrm{C} .{ }^{1} \mathrm{H}$ NMR (DMSO-d6, $400 \mathrm{MHz}) \delta$ : $8.66(1 \mathrm{H}, \mathrm{d}, J=5.0 \mathrm{~Hz}, \mathrm{H}-1), 7.95$ (1H, s, H-5), $7.49(1 \mathrm{H}, \mathrm{d}, \mathrm{J}=2.2 \mathrm{~Hz}, \mathrm{H}-3), 7.47$ $(1 \mathrm{H}, \mathrm{d}, J=2.2 \mathrm{~Hz}, \mathrm{H}-4), 6.90(1 \mathrm{H}, \mathrm{d}, J=5.0 \mathrm{~Hz}$, $\mathrm{H}-2), 3.04(4 \mathrm{H}, \mathrm{d}, J=5.1 \mathrm{~Hz}, \mathrm{H}-6, \mathrm{H}-6$ '), 2.95 $\left(4 \mathrm{H}, \mathrm{d}, \mathrm{J}=5.3 \mathrm{~Hz}, \mathrm{H}-7, \mathrm{H}-7\right.$ '); ${ }^{13} \mathrm{C}$ NMR (DMSOd6, $100 \mathrm{MHz}) \delta: 157.3\left(\mathrm{C}_{4}\right), 152.6\left(\mathrm{C}_{2}\right), 150.1$ $\left(\mathrm{C}_{9}\right), 133.9\left(\mathrm{C}_{7}\right), 128.5\left(\mathrm{C}_{8}\right), 126.5\left(\mathrm{C}_{6}\right), 126.0$ $\left(\mathrm{C}_{5}\right), 121.9\left(\mathrm{C}_{10}\right), 109.6\left(\mathrm{C}_{3}\right), 53.7\left(\mathrm{C}_{11}\right), 46.0$ $\left(\mathrm{C}_{12}\right)$. Mass Spectrum (esi): 246(12\%), 231(15), 217(11), 207(28), 205(100\%), 191(15), 177(55), 169(18), 164(58). Elemental Analysis: Calculated: $\left(\mathrm{C}_{13} \mathrm{H}_{14} \mathrm{~N}_{3} \mathrm{Cl}\right): \mathrm{C}=63.0 \% ; \mathrm{H}=5.65 \%$;
$\mathrm{N}=16.9 \%) ;$ Found: $\mathrm{C}=63.08 \% ; \mathrm{H}=5.63 \% ; \mathrm{N}=$ $16.7 \%)$.

Formation of impurity: 1,4-Bis-(4,7dichloroquinoline)piperazine (3)

A reaction vessel equipped with a stirring apparatus, heat source, and a reflux condenser was charged with 1 (3.90 g, $19.7 \mathrm{mmol}), 15 \%$ aq $\mathrm{HCl}$ (19.5 mL, approximately 5.0 volumes w/v) and piperazine $(1.0 \mathrm{~g}, 11.8 \mathrm{mmol}, 0.6 \mathrm{~mol} \mathrm{eq})$. The stirred suspension was then heated to reflux, resulting in a clear, yellow-orange solution. The reaction was monitored by TLC for completion (reaction time approximately $16 \mathrm{~h})$. TLC (3:97 EtOAc : Hexane; silica gel). When the reaction was complete, the source of heat was removed and stirring i continued for $30 \mathrm{~min}$. Compound 3 was isolated by filtration as a pink solid and dried to a constant weight of $2.70 \mathrm{~g}(70.1 \%$ yield $) .{ }^{1} \mathrm{H}$ NMR (DMSO-d6, $400 \mathrm{MHz}) \delta: 8.76(2 \mathrm{H}, \mathrm{d}, J=$ $\left.6.8 \mathrm{~Hz}, \mathrm{H}-1, \mathrm{H}-1^{\prime}\right), 8.25$ (2H, s, H-5, H-5'), 8.15 $\left(2 \mathrm{H}, \mathrm{d}, \mathrm{J}=2.0 \mathrm{~Hz}, \mathrm{H}-3, \mathrm{H}-3^{\prime}\right), 7.71$ and $7.69(2 \mathrm{H}$, $\mathrm{dd}, J=2.0 \mathrm{~Hz}, \mathrm{H}-4, \mathrm{H}-4$ '), $7.20(2 \mathrm{H}, J=6.8 \mathrm{~Hz}$, $\mathrm{H}-2, \mathrm{H}-2$ '), $6.0(8 \mathrm{H}$, br s, $8 \times \mathrm{H}-6) ;{ }^{13} \mathrm{C}$ NMR (DMSO-d6, $100 \mathrm{MHz}) \delta: 171.5\left(\mathrm{C}_{4}, \mathrm{C}_{4}\right), 145.3$ $\left(\mathrm{C}_{2}, \mathrm{C}_{2^{\prime}}\right), 140.4\left(\mathrm{C}_{9}, \mathrm{C}_{9^{\prime}}\right), 138.9\left(\mathrm{C}_{7}, \mathrm{C}_{7^{\prime}}\right), 127.9$ $\left(\mathrm{C}_{8}, \mathrm{C}_{8}\right), 126.5\left(\mathrm{C}_{6}, \mathrm{C}_{6}\right), 120.3\left(\mathrm{C}_{5}, \mathrm{C}_{5^{\prime}}\right), 119.1$ $\left(\mathrm{C}_{10}, \mathrm{C}_{10^{\prime}}\right), 106.8\left(\mathrm{C}_{3}, \mathrm{C}_{3}\right)$; Mass Spectrum (esi) $\mathrm{m} / \mathrm{z} \quad 411(\mathrm{M}+2 ; \quad 60 \%), \quad 409(100 \%), \quad 246(15)$, 231(20), 217(15), 205(90), 177(60), 164(52). Elemental Analysis: Calculated: $\left(\mathrm{C}_{22} \mathrm{H}_{18} \mathrm{~N}_{4} \mathrm{Cl}_{2}\right)$ : C $=64.48 \% ; \mathrm{H}=4.40 \% ; \mathrm{N}=13.68 \%) ;$ Found: $\mathrm{C}$ $=64.36 \% ; \mathrm{H}=4.49 \% ; \mathrm{N}=13.71 \%$ ).

\section{Step two}

\section{1,3-bis(1-7'-chloro-4-quinolyl-4- piperazinyl)propane; piperaquine free base}

$A$ reaction vessel equipped with a stirring apparatus, heat source, and a reflux condenser was charged with 1 (67.5 g, $0.273 \mathrm{~mol})$, 2propanol (170 $\mathrm{mL}$, approximately 2.5 volumes $\mathrm{w} / \mathrm{v})$ and water (390 mL, 5.8 volumes $\mathrm{w} / \mathrm{v})$. The stirred suspension was then charged with potassium carbonate $(75.4 \mathrm{~g}, 0.55 \mathrm{~mol}, 2.0 \mathrm{~mol}$ eq) and 1,3-dibromopropane $(24.8 \mathrm{~g}, 0.123 \mathrm{~mol}$, $0.46 \mathrm{~mol}$ eq). The stirred suspension was heated to reflux and monitored by TLC (80:20:4 $\mathrm{CHCl}_{3}: \mathrm{MeOH}: \mathrm{AcOH}$ on silica gel, with iodine visualization). The reaction took approximately 6 $\mathrm{h}$ to reach completion. The reaction mixture was stirred with cooling and maintained at ambient temperature for at least $1 \mathrm{~h}$ before isolation of the crude free base of piperaquine by filtration. Drying of the crude material to a constant weight gave an isolated yield of $62.4 \mathrm{~g}(94.8 \%$ yield $)$. A yellowish-white solid, mp: $165{ }^{\circ} \mathrm{C} .{ }^{1} \mathrm{H}$ NMR (DMSO-d6, $400 \mathrm{MHz}) \delta$ : $8.79(1 \mathrm{H}, \mathrm{d}, J=5.0 \mathrm{~Hz}$, $\mathrm{H}-1), 8.70\left(1 \mathrm{H}, \mathrm{d}, J=5.0 \mathrm{~Hz}, \mathrm{H}-1^{\prime}\right), 8.16(1 \mathrm{H}, \mathrm{d}, J$ $=9.0 \mathrm{~Hz}, \mathrm{H}-5), 8.04\left(1 \mathrm{H}, \mathrm{d}, J=2.9 \mathrm{~Hz}, \mathrm{H}-5{ }^{\prime}\right)$, 
$8.03(1 \mathrm{H}, \mathrm{d}, J=3.6 \mathrm{~Hz}, \mathrm{H}-3), 7.97(1 \mathrm{H}, \mathrm{d}, J=2.0$ $\mathrm{Hz}, \mathrm{H}-3$ '), 7.62 (2H, dddd, $J=2.0,2.0,2.0,2.2$ $\mathrm{Hz}, \mathrm{H}-4, \mathrm{H}-4$ ') $7.16(1 \mathrm{H}, \mathrm{d}, J=5.0 \mathrm{~Hz}, \mathrm{H}-2)$,

$7.0\left(1 \mathrm{H}, \mathrm{d}, J=5.0 \mathrm{~Hz}, \mathrm{H}-1^{\prime}\right), 3.50(2 \mathrm{H}, \mathrm{s}, \mathrm{H}-9)$, $3.10(8 \mathrm{H}, \mathrm{d}, J=4.9 \mathrm{~Hz}, \mathrm{H}-6, \mathrm{H}-6$ '), $3.00(4 \mathrm{H}, \mathrm{s}$, $\left.\mathrm{H}-8, \mathrm{H}-8^{\prime}\right), 2.97$ (8H, d, J = 4.7 Hz, H-7, H-7'); ${ }^{13} \mathrm{C}$ NMR (DMSO-d6, 100 MHz) ס: 157.4 (C4, C4'), $152.6\left(\mathrm{C}_{2}, \mathrm{C}_{2^{\prime}}\right), 150.0\left(\mathrm{C}_{9}, \mathrm{C}_{9^{\prime}}\right), 134.0\left(\mathrm{C}_{7}, \mathrm{C}_{7^{\prime}}\right)$, $128.3\left(\mathrm{C}_{8}, \mathrm{C}_{8^{\prime}}\right), 126.6\left(\mathrm{C}_{6}, \mathrm{C}_{6}\right), 126.1\left(\mathrm{C}_{5}, \mathrm{C}_{5^{\prime}}\right)$, $121.8\left(\mathrm{C}_{10}, \mathrm{C}_{10}\right), 109.7\left(\mathrm{C}_{3}, \mathrm{C}_{3^{\prime}}\right), 62.6\left(\mathrm{C}_{14}\right), 53.5$ $\left(\mathrm{C}_{11}, \mathrm{C}_{11^{\prime}}\right), 45.8\left(\mathrm{C}_{12}, \mathrm{C}_{12^{\prime}}\right), 34.0\left(\mathrm{C}_{13}\right), 25.8\left(\mathrm{C}_{13^{\prime}}\right)$; Mass Spectrum (esi) $\mathrm{m} / \mathrm{z} \quad 539(\mathrm{M}+4 ; 10 \%)$, 538(M+3; 25), 537(M+2; 65), 535(100\%); 290(35); 288(100); 260(30), 245(18), 217(15). Elemental Analysis: Calculated: $\left(\mathrm{C}_{29} \mathrm{H}_{32} \mathrm{~N}_{6} \mathrm{Cl}_{2}\right)$ : C $=65.0 \% ; \mathrm{H}=6.03 \% ; \mathrm{N}=15.70 \%)$; Found: $\mathrm{C}=$ $64.89 \% ; H=6.07 \% ; N=15.71 \%)$.

\section{Synthesis of Piperaquine tetraphospate}

A suitable reaction vessel was charged with the product from step two $(62.4 \mathrm{~g}, 0.117 \mathrm{~mol})$ and stirred as an ice-chilled suspension with $250 \mathrm{~mL}$ (4 volumes w/v) of water. Aqueous, $85 \%$ phosphoric acid $\left(\mathrm{H}_{3} \mathrm{PO}_{4}, 27.1 \mathrm{~mL}, 0.47 \mathrm{~mol}, 4.0\right.$ mol eq) was added over a minimum of $1 \mathrm{~h}$, followed by warming to room temperature and stirring for another $2 \mathrm{~h}$. The product was isolated by filtration and allowed to air dry to a constant weight. The recovery of piperaquine as the corresponding tetrahydrate of the tetraphosphate salt (MW 999.56) was nearly quantitative (about $117 \mathrm{~g}$ on an anhydrous basis).

\section{RESULTS}

One legal requirement for the granting of a patent is that the inventors disclose the best method of practicing the described invention. Using experimental details from existing patent filings $[23,25,26]$, we estimate that various processes disclosed for the production of piperaquine utilize somewhere between 32 and $55 \mathrm{~kg}$ of organic solvent (w/v) per kilogram of product produced. The overall yield of piperaquine phosphate from $D C Q$ for these processes seemed to be in the range of $52-65$ $\%$. In addition, dichloromethane, acetonitrile, and $\mathrm{N}, \mathrm{N}$-dimethylformamide are solvents used during processing. These solvents present environmental or toxicological difficulties for use, handling, and disposal. Each of these was also extremely difficult to recycle. We have attempted to improve upon previous processes in the choice of solvent, volumes of solvent used, telescoping together of multiple operations, and overall yield.

The reaction of $D C Q$ with 3 mole equivalents of piperazine in 2.5 volumes (w/v) of 2-propanol at reflux yielded 1 in very high chemical yield (> 96
$\%$ in solution as determined by HPLC analysis). Most notably, under these conditions impurity 3 was either completely absent or generated at levels of not more than $0.2 \%$ (HPLC analysis). When the chemical reaction to produce 1 was finished, ethyl acetate ( 5 volumes $w / v$ ) is added to the reaction and the resulting suspension was filtered to remove precipitated piperazine. Approximately 1.3 mole equivalents of piperazine was recovered by this filtration; recovered material has been recycled for use in making subsequent batches of piperaquine. The ethyl acetate layer was then washed with water to remove residual piperazine, leaving $\mathbf{1}$ in the organic layer. Ethyl acetate was partially removed by distillation (to about 2 volumes w/v vs. product) and compound $\mathbf{1}$ is isolated by filtration. For step two, intermediate 1 is reacted with 1,3-dibromopropane using potassium carbonate as base in a mixed solvent of 2propanol : water (Figure 2).

It is critical that the charge of 1,3dibromopropane be carefully controlled so that 1 is present in a slight excess during step two. Excess 1,3-dibromopropane present in the reaction mixture gives rise to impurities that are difficult to remove from piperaquine by extraction or crystallization. The piperaquine free base was isolated in high yields by direct filtration from the reaction suspension at ambient temperature; some upgrading of the purity of material occurs at this stage as process impurities were removed into the aqueous 2-propanol reaction liquors. Piperaquine free base may be processed as a wet cake and was converted to the desired tetraphosphate salt by addition of phosphoric acid to an aqueous suspension of the wet cake. This process yielded piperaquine as the tetrahydrate form of its tetraphosphate salt in 92$93 \%$ overall yield from DCQ, with none of the toxic impurity 3 present (< $0.03 \%$ ). The technology employed is robust and seems appropriate for implementation in resourcelimited settings. Minimal amounts of waste are generated during the process (roughly $8 \mathrm{~kg} / \mathrm{kg}$ of API free base), of which about $60 \%$ was directly recoverable by distillation of ethyl acetate as a single solvent. The recovery and recycling of approximately $65 \%$ of the excess, unreacted piperazine used in the process has also been successfully demonstrated. Related substances in the final piperaquine tetraphosphate were all below $0.1 \%$ as determined by HPLC analysis.

\section{DISCUSSION}

This article discloses an efficient, convenient synthesis of the API piperaquine tetraphosphate. The overall yield is approximately $92-93 \%$, 
with very low levels of related substances (each individual impurity $<0.1 \%$ ). This process generates a limited amount of organic waste (about $8 \mathrm{~kg} / \mathrm{kg}$ of product) of which roughly $60 \%$ can be recycled by distillation as a single solvent (ethyl acetate).

The direct reaction of $D C Q$ with piperazine can be successfully carried out in a number of solvents (e.g., ethanol, 1- and 2-propanol, acetic acid, 1-butanol, N,N-dimethylformamide, Nmethylpyrrolidinone, dimethylsulfoxide, N,Ndimethylacetamide, and water). As discussed above, the generation of impurity $\mathbf{3}$ is the most important element to control at this stage. Base (most often $\mathrm{K}_{2} \mathrm{CO}_{3}$ ) was added to these reactions by previous investigators, as one mole equivalent of hydrochloric acid is generated during processing. Under these conditions, or using 2.5 equivalents or less of piperazine, we observed the formation of several percent or more of impurity 3. We initially attempted to use water as the solvent for this reaction. $D C Q$ is only very modestly soluble in water, but step one can be accomplished quite effectively in aqueous hydrochloric acid. The reaction of DCQ with 3 mole equivalents of piperazine in 4 volumes $(\mathrm{w} / \mathrm{v})$ of $9.25 \%$ aqueous hydrochloric acid at reflux gives complete conversion to 1 (1-2 hours on $200 \mathrm{~g}$ scale) which may be isolated as the corresponding hydrochloride salt. HPLC analysis indicates that the chemical yield of this reaction is about $94 \%$ with modest amounts of product remaining in the reaction liquors (85\% isolated yield). Importantly, we noted that under these conditions impurity 3 could not be detected in the reaction mixture by HPLC.
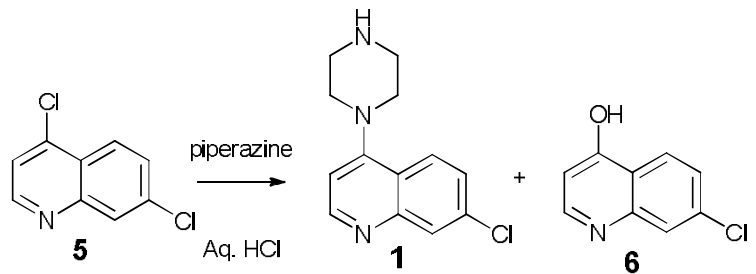

Figure 4: 7-chloro-quinolin-4-ol 6 in Step one

One drawback to the use of water for this reaction, however, was the need to separate 1 from unreacted piperazine, as these were seen to co-crystallize from aqueous solutions as either the free base or hydrochloride salts (depending upon the presence of hydrochloric acid). In addition, about 3-6\% percent of an impurity (compound 6; Figure 4) was formed in aqueous solutions during step one. Finally, practical problems made it inconvenient to recover 1 in the free base form that is required for step two of the synthesis. We had previously noted, however, that carrying out step one in 2-propanol without added base significantly suppressed the production of unwanted dimer 3. Apparently the impact of generating a full mole equivalent of hydrochloric acid during this reaction substantially decreases the rate of dimer formation by protonating the product and reducing its reactivity. This effect was confirmed by carrying out step one in either water or 2propanol with modest amounts (1-3 mol eq) of hydrochloric acid present. This modification produced essentially no impurity 3 as seen by HPLC analysis $(0.00-0.20 \%)$ of the reaction mixture and isolated intermediate 1. Although water is generally preferred for reactions based on "green chemistry" concepts, we found that a minimum of 2-propanol (2.5 volumes, w/v) was preferred for this reaction in order to conveniently separate compound $\mathbf{1}$ from piperazine and to isolate this intermediate in its free base form. Piperazine must be rigorously excluded from step two in order to avoid the formation of related process impurities. The conditions described in this manuscript for the workup and isolation of step one provide an easier means of separating 1 from piperazine than when water is the reaction solvent.

One important factor in assuring successful chemical production is to develop a process that can be routinely reproduced by people who are not trained chemists. The synthesis described here was successfully replicated by twenty-three individuals attending the St Luke Foundation/ Kilimanjaro School of Pharmacy training course in Industrial Pharmacy and GMP drug production in August, 2011 in Moshi, Tanzania. The technology is simple and robust, and yields API that meets all requirements for processing forward into FPPs.

\section{CONCLUSION}

We have successfully implemented an alternative, green-chemical synthesis of piperaquine tetraphosphate. This synthesis is carried out in two chemical steps and an overall yield of about $92-93 \%$. This synthesis generates approximately $8 \mathrm{~kg}$ of organic waste per kilogram of product produced. Approximately $60 \%$ of this waste can be recovered and recycled in the form of crystalline piperazine and ethyl acetate. HPLC analysis confirms that the piperaquine phosphate produced is very pure (related substances each not more than $0.1 \%$ and total NMT $0.5 \%$ ). The isolated product is obtained in the correct salt form and in sufficient purity for use in preparing artemisinin combination therapies. This synthesis would seem to fit the requirements for utilization in a 
resource-limited setting for production of the API and finished product ACTs.

\section{ACKNOWLEDGEMENT}

An American Chemical Society GREET Fellowship provided support for CL King and JMD Fortunak for portions of this work. The United Nations Industrial Development Organization (UNIDO) provided support for the Industrial Pharmacy Training Program at the St Luke Foundation/Kilimanjaro School of Pharmacy where this work was replicated. Support from the William J. Clinton Health Access Initiative (CHAI) for analytical methods development and HPLC assays is gratefully acknowledged.

\section{REFERENCES}

1. Mathers $C D$, Ezzati M, Lopez AD. Measuring the Burden of Neglected Tropical Diseases: The Global Burden of Disease Framework. PLoS Negl Trop Dis 2007; 1(2): e114-129.

2. Hasugian AR, Purba HLE, Kenangalem E, Wuwung RM, Ebsworth EP, Maristela R, Penttnen PMP, Laihad $E$, Anstey NM, Tjitra E, et al. DihydroartemisininPiperaquine versus Artesunate-Amodiaquine: Superior treatment and post-treatment prophylaxis against multidrug-resistant Plasmodium falciparum and Plasmodium vivax malaria. Clin Infect Dis 2007; 44: 1067-1074.

3. The President's Emergency Plan for AIDS Relief (PEPFAR). [Homepage on the Internet]. Washington, DC, (USA): [cited 2012, May 4]. Available from: $h t t p: / / w w w$.avert.org/pepfar.htm.

4. The Global Fund to Fight AIDS, Tuberculosis and Malaria. [Homepage on the Internet]. Geneva, (CH): [cited 2012, May 11]. Available from: http://www. theglobalfund.org/en/

5. The Affordable Medicines Facility for Malaria [homepage on the internet]. Hosted by the Roll Back Malaria Venture of the World Health Organization, Geneva (CH): [Cited 2012, March 3] Available from: http://www.rbm.who.int/psm/amfm.html.

6. AMFm making effective malaria treatment affordable and available. [cited 2011, March 30] Available from: http://www.vanguardngr.com/2011/03/amfmmaking-effective-malaria-treatment-affordable-andavailable/.

7. Sidhu ABS, Verdier-Pinard D, Fidock DA. Chloroquine Resistance in Plasmodium falciparum Malaria Parasites Conferred by pfcrt Mutations. Science 2002; 298: 210-213.

8. World Health Organization. World Malaria Report: 2008. Geneva, World Health Organization Publication, 2008. ISBN 978924156369 7; 190 pp.

9. World Health Organization. World Malaria Report: 2008. Geneva, World Health Organization Publication, 2008. ISBN 978924156369 7; 190 pp.; pp. 131 140.

10. World Health Organization. World Malaria Report: 2008. Geneva, World Health Organization Publication, 2008. ISBN 978924156369 7; 190 pp.; pg. 10.
11. WHO - Health Systems and Services: Prequalification of Medicines Programme [Homepage on the Internet]. Geneva, (CH): Prequalification Programme: A United Nations Programme managed by WHO. [cited 2012, June 25]. Available from: http://apps.who.int/prequal/.

12. FDA - US Food and Drug Administration (Drugs) [Homepage on the Internet]. Guidance, Compliance, and Regulatory Information. Bethesda, (USA): [Cited 2012, June 17]. Available from: http://www.fda.gov/Drugs/GuidanceComplianceR egulatory/nformation/default.htm.

13. International Conference on Harmonisation of Technical Requirements for Registration of Pharmaceuticals for Human Use. [Homepage on the Internet]. Geneva, (CH): [Cited 2012, June 11]. Available from: http://www.ich.org/

14. World Health Organization. The Quality of Anti-malarials in Sub-Saharan Africa (QAMSA) Study. [cited 2012, June 1]. Available at: http://apps.who. int/prequal/info_general/documents/QC_Labs/QAM SA Report.pdf

15. Editor-in-Chief. Pharmaceutical Manufacturing in Kenya. Med J Therapeutics, Africa 2009; 3(2): 59-61.

16. Losse K, Schneider E, Spennerman C. The viability of local pharmaceutical production in Tanzania, 2009. [Cited 2012, February 3]. Available from: http://www.gtz.de

17. Henfrey P. Artemisinin production in East Africa. Presented at the Artemisinin Conference, November 2011: Arusha (TZ). [cited 2012, May 24]. Available from: http://www.a2s2.org/ ArtemisininConference2011/Day1/08d.BotanicalE xports.pdf.

18. World Health Organization. Facts on ACTs; Section II: WHO Recommendations on Malaria Treatment. [cited 2012, January 23]. Available from: http://www.rollbackmalaria.org/cmc_upload/0/000/ 015/364/RBMInfosheet_9.htm.

19. Zwang J, Ashley EA, Karema C, D'Alessandro $U$, Smithuis $F$, Dorsey $G$, Janssens $B$, Mayxay $M$, Newton $P$, Singhasivanon $P$, et al. Safety and Efficacy of Dihydroartemisinin-Piperaquine in Falciparum Malaria: A Prospective Multi-Centre Individual Patient Data Analysis. PLoS ONE 2009; 4(7): e6358, 1-13

20. Sigma Tau Pharmaceuticals Ltd., Application for inclusion of dihydroartemisinin plus piperaquine (DHA/PPQ) fixed dose combination tablets in the $17^{\text {th }}$ edition of the WHO model lists of essential medicines. [cited 2012, January 26]. Available from: http://www.who.int/selection medicines/committee es/expert/18/applications/D_Piperaquine.pdf.

21. Lindegargh N, Georgi $F$, Galleti $\bar{B}$, Di Mattia M, Quaglia M, Carnevale D, White NJ, Mazzanti A, Day NPJ. Identification of an isomer impurity in piperaquine drug substance. J Chromatogr A 2006; 1135: 166169.

22. US Patent 5,510,356 issued 23 April, 1996.

23. US Patent 3,173,918 issued 16 March, 1965.

24. Burckhalter JH, DeWald HA, Tendick FH. An Alternative Synthesis of Camoquin. J Am Chem Soc 1950; 72(2): 1024-1025.

25. US Patent application 2006/0270852 A1 published 30 November, 2006

26. International Patent application WO 2009/050734 A2, published 23 April, 2009. 